\title{
O PODER NORMATIVO DO CONTRAN E SEUS REFLEXOS NAS RELAÇÕES CONTRATUAIS ADMINISTRATIVAS
}

\author{
ALEXANDRE SANTOS DE ARAGÃO* \\ O poder normativo do CONTRAN - Reflexos nas relações contratuais \\ administrativas - Conclusões
}

O presente estudo versa sobre a legitimidade e aplicabilidade da Resolução CONTRAN $n^{\circ} 141$, que dispõe sobre o uso, a localização, a instalação e a operação de aparelho, de equipamento ou de qualquer outro meio tecnológico para auxiliar na gestão do trânsito, e em seu art. 19 dispõe:

Art. 19. O comprovante de infração a que se refere esta Resolução, emitido por aparelho, por equipamento ou por qualquer outro meio tecnológico, se disponibilizado ao órgão ou entidade de trânsito em virtude de contrato celebrado com terceiros, com cláusula que estabeleça remuneração com base em percentual ou na quantidade das multas aplicadas, não poderá servir para imposiçāo de penalidade, devendo somente ser utilizado para auxiliar a gestão de trûnsito.

Parágrafo Único. Os órgãos e entidades do Sistema Nacional de Trânsito - Denatran terão prazo de trinta (30) dias, contados a partir da publicação desta Resolução, para dar cumprimento ao disposto no caput deste artigo.

Relata a autoridade consulente que, segundo as cópias juntadas aos autos, celebrou contratos com empresas privadas para a operação de sistemas eletrônicos

* Professor-Assistente do Mestrado da Faculdade de Direito da Universidade Candido Mendes. Professor da Pós-graduação em Direito do Estado da Universidade do Estado do Rio de Janeiro U.E.R.J. Procurador do Estado e Advogado no Rio de Janeiro. Membro do IBAP e do IAB (alexaragao@zipmail.com.br).

R. Dir. Adm., Rio de Janeiro, 230: 305-313, Out./Dez. 2002 
de fiscalização da velocidade dos veículos que transitam por suas vias, tendo sido estabelecido que estas são remuneradas mediante a percepção de determinada percentagem incidente sobre o valor efetivamente arrecadado das multas decorrentes das suas atividades ou um valor fixo a estas correspondentes (cf. fls. 49 e 94, respectivamente).

Se. por um lado. este modo de pagamento faz com que se assegure que as empresas contratadas sejam aplicadas no desempenho de suas funções, por outro, pode incentivá-las a cometer excessos na aplicação da maior quantidade possível de multas, incentivando a tão falada "indústria das multas".

Note-se que o texto da Resolução não chega propriamente a proibir a remuneração proporcional às multas pagas, dispondo tão-somente que as infrações de trânsito constatadas em razão destes contratos não poderão acarretar a aplicação de penalidade, devendo somente ser levadas em consideração para auxiliar a gestão de trânsito.

Não há como se negar, todavia, a enorme incidência da norma do CONTRAN sobre estes contratos, que. obviamente, pressupõem a possibilidade de cobrança das multas correspondentes às infrações verificadas. de cujo pagamento resultaria a remuneração da contratada. Em outras palavras, esta possibilidade corresponde ao próprio substrato dos contratos. ${ }^{2}$

Desta forma, em um primeiro momento analisaremos a legitimidade do poder regulamentar exercido pelo CONTRAN para editar a indigitada Resolução $\mathrm{n}^{\circ} 141$; e, em seguida, os seus reflexos nas relações contratuais mantidas pelo DER-RJ.

\section{O poder normativo do CONTRAN}

O Código de Trânsito Brasileiro - CTB elegeu o Conselho Nacional de Trânsito - CONTRAN como o órgão normativo central do sistema nacional de trânsito. ${ }^{3}$ já que seria impossível que o próprio Legislador, com a celeridade e a especialização técnica necessárias, permanecesse diuturnamente regulando as matérias atinentes ao trânsito. ${ }^{4}$

1 " Verificou-se que a Administração agia com falsa discricionariedade. substituindo o interesse público por interesse claramente arrecadador e violador, portanto, dos direitos individuais e da razoabilidade. Essa foi a constatação do que ficou conhecido como a 'indústria da multas", alvo até de disputas judiciais" (FERNANDES, Daniel André. Os Princípios da Razoabilidade e da Ampla Defesa. Ed. Lumen Juris, Rio de Janeiro. 2002. p. 116).

2 Desta maneira, a Resolução Contran $n^{\circ} 141$ pode ser subsumida ao que Orlando Gomes se refere como acontecimentos extraordinários que determinam radical alteração no estado de fato e/ou de direito contemporâneo à celebração do contrato (GOMES. Orlando. Contratos. Ed. Forense. Rio de Janeiro. $12^{2}$ edição, 1987. pp. 41 e 42).

3 Art. $7^{\circ}$ Compõem o Sistema Nacional de Trânsito os seguintes órgãos e entidades: I -- o Conselho Nacional de Trânsito - CONTRAN, coordenador do Sistema e órgão máximo normativo e consultivo.

+ "Por serem privativas da União. e, por isso, se conferem todas no Código Brasileiro de Trânsito, não apresentam problemas de competência, mas é necessário ter-se em conta que um grande número 
Como já tivemos a oportunidade de afirmar em sede doutrinária, ${ }^{5}$ o pluralismo e complexidade da sociedade, agregados ao número cada vez maior de atividades dotadas de grandes particularidades técnicas a serem, se não prestadas diretamente pelo Estado, por ele reguladas, inviabilizou o ideal liberal oitocentista, ${ }^{6}$ racional e formalmente igualitário, de um ordenamento monocêntrico uniforme que, concebido de maneira inteiramente geral e abstrata, abrangesse todas as atividades e atores sociais sem levar em conta as suas particularidades. ${ }^{\text {? }}$

Nas palavras de A. ROMANO, "o desenho complexivo que parece surgir das recentes leis sobre o poder regulamentar é aquele de uma repartição das competências normativas entre Parlamento e Governo que vê confiada ao primeiro as escolhas de fundo (os princípios) da disciplina, enquanto a normatização atuativa dos princípios em si é emanada pelo Executivo. (...) A lógica é aquela de reservar ao Parlamento apenas as grandes, importantes (e presumivelmente duráveis) opções políticas, enquanto a adequação da disciplina mais detalhista às mutáveis exigências do mundo contemporâneo é confiada a fontes mais ágeis e capazes de uma mais rápida intervenção." 8

Inicialmente, a complexidade social levou o legislador a elaborar regulamentações especiais destinadas a determinados setores da sociedade ou a certas relações jurídicas.

Posteriormente, verificou-se que não bastava a edição de leis especiais pelo Poder Legislativo. Impunha-se também a especialização das fontes do Direito e dos respectivos órgãos emanadores. O Poder Legislativo, essencialmente político e atuando mediante processos necessariamente lentos, viu-se incapaz de lidar com a complexidade, pluralidade e tecnicismo das matérias que demandavam a sua atuação.

Vejamos, sob esta perspectiva, os fundamentos legais da Resolução CONTRAN $n^{\circ} 141:$

delas se desdobram secundariamente em sete grupos de normas administrativas regulamentares. baixadas por órgãos dos três níveis federativos" (MOREIRA NETO, Diogo de Figueiredo. Comperências Administrativas de Polícia no Código de Trânsito Brasileiro. in RDPGE. 51/139).

5 ARAGÃO, Alexandre Santos de. Agências Reguladoras e a Evolução do Direito Administrativo Econômico, Ed. Forense, Rio de Janeiro, pp. 379-418.

6 O ideal liberal clássico pretendeu concretizar-se principalmente através da codificação das normas jurídicas, o que levaria à sistematização racional de todas elas em apenas um diploma legislativo. Tratando do malogro da codificação. Henri De Page, com a elegância de estilo e erudição que lhe é peculiar, vivenciou da seguinte forma o centenário do Código Civil Francês: "A fé na codificação se enfraqueceu. Pomos a mão na testa quando falam de sua eficácia. Nós a criticamos com amargura. Com cem anos de idade. pensamos no Código Civil, mas mais para the desejar um 'enterro honroso': e a celebração de um centenário parece mais com uma oração fúnebre do que com uma solenidade glorificante" (in De L'Interprétationdes Lois, Tome Premier. Payot \& Cie.. Bruxelas, 1925, pp. 19 e 20).

7 Para aprofundamento deste ponto da concepção liberal do direito, de grande atualidade é a obra de MORAND, Charles-Albert. Le Droit Néo-Moderne des Politiques Publiques. LGDJ, Parıs. 1999. pp. 29/32.

8 ROMANO, A. Diritto Amministrativo, AA. VV., Monduzi Editore. $3^{\mathrm{a}}$ ed.. 2001 , p. 234. 
Art. 12. Compete ao CONTRAN:

I - estabelecer as normas regulamentares referidas neste Código e as diretrizes da Política Nacional de Trânsito;

II a VII - oimissis;

VIII - estabelecer e normatizar os procedimentos para a imposição, a arrecadação e a compensação das multas por infraçōes cometidas em unidade da Federação diferente da do licenciamento do veículo:

IX e X-omissis;

$X I$ - aprovar, complementar ou alterar os dispositivos de sinalização e os dispositivos e equipamentos de trânsito;

XIl a XIV-omissis.

Art. 22. Compete aos órgãos ou entidades executivos de trânsito dos Estados e do Distrito Federal, no âmbito de sua circunscrição:

I a IX - omissis;

$X$ - credenciar órgãos ou entidades para a execução de atividades previstas na legislação de trânsito, na forma estabelecida em norma do CONTRAN; XI a XVI - omissis.

Art. 280. Ocorrendo infração prevista na legislação de trânsito, lavrar-se-á auto de infração, do qual constará:

I a VI-omissis.

$\S 2^{\circ}$. A infração deverá ser comprovada por declaração da autoridade ou do agente da autoridade de trânsito, por aparelho eletrônico ou por equipamento audiovisual, reações quimicas ou qualquer outro meio tecnologicamente disponivel, previamente regulamentado pelo CONTRAN.

As leis que, como o CTB, atribuem com tal amplitude poder normativo a órgãos da Administração Pública possuem baixa densidade normativa, a fim de - ao estabelecer finalidades e parâmetros genéricos — propiciar, em maior ou em menor escala, o desenvolvimento de normas setoriais aptas a, com autonomia e agilidade, regular a complexa e dinâmica realidade social subjacente. ${ }^{9}$

J. J. GOMES CANOTILHO ${ }^{10}$ denota que "as leis continuam como elementos básicos da democracia política (...), mas deve reconhecer-se que elas se transforma-

9 ARAGÃO, Alexandre Santos de. Agências Reguladoras e a Evolução do Direito Administrativo Econômico, Ed. Forense. Kio de Janeiro, pp. 379-418.

10 CANOTILHO, J.J. Gomes. Relatório sobre Programa, Conteudos e Métodos de Um Curso de 
ram numa política pública cada vez mais difícil, tornando indispensável o afinamento de uma teoria geral da regulação jurídica. (...) A idéia de que a lei é o único procedimento de regulação jurídico-social deve considerar-se ultrapassada (A. Rhinow, N. Achterberg, U. Karpen, E. Baden). A lei é, ao lado das decisões judiciais e das 'decisões' da administração, um dos instrumentos da regulação social."

Podemos ver, com efeito, que o CONTRAN possui competências normativas calcadas em standards, ou seja, em palavras dotadas de baixa densidade normativa, às vezes meramente habilitadoras, devendo exercer estas competências na busca da realização das finalidades públicas - também genéricas - fixadas no CTB. ${ }^{11}$

As leis com estas características não dão maiores elementos pelos quais o administrador deva pautar a sua atuação concreta ou regulamentar, referindo-se genericamente a parâmetros a serem observados. Assim, confere à Administração Pública um grande poder de integração do conteúdo da vontade do legislador, dentro dos quadros por ele estabelecidos. O objetivo das leis assim formuladas é "introduzir uma vagueza que permita o trato de fenômenos sociais, muito fugazes para se prestarem ao aprisionamento em uma regra precisa." 12

A lei, portanto, sem dar início de per se a uma normatização mais completa, e, muito menos, exaustiva da matéria, estabelece apenas parâmetros bem gerais, um quadro legal, da regulamentação a ser feita pela entidade ou órgão administrativo competente.

Nestes casos, o que temos na realidade, é a execução pela Administração Pública da Lei, que, contudo, deixou de estabelecer maiores detalhamentos quanto à matéria legislada, fixando apenas standards e finalidades gerais. Não é o fato de a Lei ter optado por adotar conceitos mais ou menos abstratos que a caracteriza como uma impensável delegação de poder legislativo, com o que toda outorga de poder regulamentar à Administração Pública consistiria em uma delegação. ${ }^{13}$

Teoria da Legislação, Separata do Vol. LXIII do Boletim da Faculdade de Direito da Universidade de Coimbra. pp. 09 e 22/3.

11 Sabino Cassese observa que a "a Administração Pública se organiza e opera no âmbito de decisões gerais determinadas pela lei. Mas estas podem variar bastante. Podem conter cânones de conduta ou apenas determinar finalidades, que vão ser alcançadas aplicando-se standards não legislativos" (CASSESE, Sabino. Le Basi del Diritto Amministrativo, Ed. Garzanti, 9* ed., Milāo, 2000, p. 442).

12 BOURCIER, Danièle. La Décision Artificielle, PUF, 1995, p. 61. Maurice Hauriou destaca a grande importância desta técnica legislativa no Direito Administrativo, vez que "o standard, flexível e mutável, representa no direito o elemento de mobilidade" (HAURIOU, Maurice. Aur Sources du Droit, Librarie Bloud \& Gay, Paris, 1993, pp. 150/1, grifamos).

13 Contrariamente, entendendo tratar-se de delegação, mas admitindo-a, pronunciou-se Rui Barbosa: "Do regular ao legislar, do legislar ao regular, nem sempre são claras as raias. Entre as duas competências medeia uma zona de fronteira, indecisa, mista, porventura comum, em que ora as leis regulamentam, ora os regulamentos legislam (...). Se contestássemos a existência de delegação e sua validade, em nome de uma doutrina abstrata, daríamos por terra com a construção de nosso direito administrativo quase todo" (apud TÁCITO, Caio, Comissão de Valores Mobiliários. Poder Regulamentar, constante do Temas de Direito Público, Ed. Renovar, Rio de Janeiro, 1997, Tomo 2, p. 1080). Em igual sentido, mais incisivamente, Miguel Reale acha que "não é exato que ao 
O que importa destacar é, nas palavras de COSTANTINO MORTATI. “a relatividade da distinção entre normativo e executivo." 14

Assim. deve ser adotado um conceito amplo de "execução", consistente no desenvolvimento de normas pré-estabelecidas, pelo qual os regulamentos calcados em standards serão "de execução", o que atende ao disposto nos arts. $5^{\circ}$, II e 84 , IV, in fine da Constituição Federal ("decretos e regulamentos para a fiel execução da lei") ${ }^{15}$

Com efeito, como adverte CARLO SALTELLI, "mesmo os regulamentos independentes não têm fundamento distinto daquele dos outros regulamentos, (...) vez que servem. como os outros regulamentos, à execução de uma lei: particularmente daquelas leis que atribuem à Administração um determinado poder, mesmo que sem discipliná-1o sequer em suas linhas gerais. Nos regulamentos de execução, a maior parte das normas concernentes a uma determinada matéria já se encontra disciplinada na lei, de maneira que o regulamento não tem outra finalidade além de acrescentar novas disposições, e a matéria permanece regulada principalmente pela lei e subsidiariamente pelo regulamento; nos regulamentos independentes, ao revés, a parte principal da disciplina da matéria é assumida pelo regulamento dada a exigüidade da norma legislativa". ${ }^{16}$

No Recurso Extraordinário n 76.629/RS, o MINISTRO ALIOMAR BALEEIRO afirmou que "se o legislador quer os fins, concede os meios. (...) Se a L. 4.862 expressamente autorizasse o regulamento a estabelecer condições outras, além das que ela estatuir, aí não seria delegação proibida de atribuições. mas flexibilidade na fixação de standards jurídicos de caráter técnico, a que se refere Stati". ${ }^{17}$

A maneira larga com que o Código de Trânsito Brasileiro - CTB revestiu o CONTRAN da competência normativa para editar a Resolução $n^{\circ} 141$ demonstra, destarte. que realizou deslegalização em favor do Conselho.

Subre esse conceito, afirma DIOGO DE FIGUEIREDO MOREIRA NETO em sua mais recente obra. ${ }^{18}$ " pode-se deduzir que a natureza da norma reguladora, por resultar de uma deslegalização. é uma norma de auto-regulação dirigida, ou seja.

\footnotetext{
Executivo só caiba a missão secundária de prover e garantir a exeqüibilidade das resoluções parlamentares, como, infelizmente, ainda pensam alguns políticos brasileiros, contrários a qualquer forma de delegação legislativa, revelando total ignorância das modernas técnicas de delegação e de controle que, assegurando ao governo processos eficazes de atualização das normas genericamertte elaboradas pelos parlamentares, a estes asseguram controle não menos eficaz, para prevenir ou reprimir abusos da Administração" (REALE. Miguel. Teoria Geral do Direito e do Estado. Ed. Saraiva. $5^{a}$ ed.. 2000. p. 353).

14 MORTA TI, Constantino. Istituzioni di Dirito Pubblico, Tomo I. Ed. CEDAM, 10 ed., Padova, 1991. p. 303.

15 ARAGÃO. Alexandre Santos de. Agências Reguladoras e a Evoluçāo do Direito Administrativo Económico. Ed. Forense. Rio de Janeiro. pp. 379-418.

16 Potere Esecutivo e Norme Gituridiche. Mantellate, Roma, 1926, pp. 103/4.

17 RTJ, 71/479. grifamos.

18 MOREIRA NETO. Diogo de Figueiredo. Direito Regulatório. Ed. Renovar. Rio de Janeiro, 2002. pp. 126 e 127 .
} 
obedece a princípios e a standards. de resto, já conhecidos. por serem de longa data de corrente emprego no ordenamento jurídico econômico e social. (...) Há duas formas de satisfazer a reserva legal, conforme o legislador opte ou pela imposição direta de condutas, predefinidas por ele próprio, ou pela disposição direta apenas de finalidades, que deverão ser detalhadas por uma fonte normativa derivada, por via da deslegalização, o que corresponde, em consequiência, a uma disposição indireta, por meio da regulação que vier a ser produzida pela fonte secundária legitimada"

\section{Reflexos nas relações contratuais administrativas}

Afirmada a legalidade da Resolução CONTRAN n 141 , mister se faz verificar as suas consequiências sobre os contratos celebrados pelos órgãos e entidades executivos de trânsito, contratos estes que, se não inquinados diretamente pela Resolução, partiram substancialmente, como visto, de pressuposto material distinto, qual seja, a até então óbvia possibilidade de as infrações constatadas pelas empresas contratadas poderem acarretar na imposição das devidas penalidades.

Pelo seu caráter genérico e abstrato, e sequer tendo sido emitida pela Administração Pública contratante (apesar disto não ser condição conceitual), podemos facilmente constatar que a Resolução CONTRAN n 141 caracteriza-se como Fato do Príncipe ${ }^{19}$ em relação aos contratos objeto do presente estudo.

O Fato do Príncipe, instituto reconduzível à Teoria Geral da Imprevisão, deve, por alterar as bases de direito nas quais o contrato se fundava. levar à revisão ou à rescisão (sem culpa) do contrato. Deve-se, contudo, considerando o Princípio da Manutenção dos Atos Jurídicos, sempre buscar a sua preservação através das revisões/alterações contratuais necessárias. Apenas se o impacto causado pelo Fato do Príncipe nas bases contratuais for de tal maneira forte que inviabilize de forma absoluta a manutenção do contrato, ${ }^{20}$ que se deverá partir para a sua rescisão.

A este respeito. vale trazer à baila as lições de MARÇAL JUSTEN FILHO, para quem "utiliza-se a expressão 'fato do príncipe' para indicar a determinação estatal que, ao disciplinar certas condutas, torna impossível o cumprimento do contrato. No fato do príncipe, o Estado introduz alteração no regime jurídico aplicável. Essa alteração se reflete na execução do contrato administrativo. Justamente porque se trata de modificação do regime jurídico. o fato do príncipe envolve

19 Diverso do Fato da Administração, que é a ação ou omissão da Administração contratante, que atinge concreta e diretamente (não é geral) o contrato. Consiste em um inadimplemento por parte da Administração contratante, que pode levar à responsabilização da Administração ou à rescisão do contrato (exemplos.: não entrega ou não desapropriação do local da obra).

20 "Como afirma Antônio Chaves. " para que a variação do objeto ou das condições principais de uma obrigação produz a sua extinção — observa Juan Ossorio Morales, transcrevendo o art. 1204 CC espanhol - 'é necessário que assim se pactue expressamente ou que a antiga e a nova obrigação sejam de todo incompatíveis" (CHAVES. Antônio. Tratado de Direito Ciril, Volume 2, Tomo 2. Ed. RT, São Paulo, 1984, p. 1.603). 
diretivas que são abstratas e impessoais. O fato do príncipe depende da edição de norma jurídica (através de lei) ou do exercício da competência regulamentar, que envolva detalhamento para melhor explicitar o conteúdo da lei. As determinações estatais aplicam-se a todos os que se encontram em situação idêntica - entre eles, o partícipe do contrato administrativo. (...) As partes deverão verificar se a execução do contrato, embora mais complexa e onerosa, permaneceu possível ou não. Se possível a continuação do contrato mediante a mera alteração das cláusulas contratuais (quanto a prazos, encargos, remuneração etc.), deverá promover-se a modificação do contrato para confirmar as alterações e restabelecer o equilíbrio econômico-financeiro." 21

No caso analisado verificamos que o fato do príncipe consubstanciado no art. 19 da Resolução CONTRAN $n^{\circ} 141$ incide sobre a forma do cálculo dos pagamentos devidos às contratadas (correspondentes às multas que vierem a ser aplicadas e pagas).

Diante da já afirmada legalidade da Resolução CONTRAN n 141 , a Administração Pública tem duas opções: celebrar novos contratos contemplando os seus ditames e até lá não se valer dos equipamentos das empresas atualmente contratadas para impor penalidades; ou adequar a forma de pagamento estabelecida nos contratos em vigor.

A Lei $n^{\circ} 8.666 / 93$ contempla expressamente esta hipótese no seu art. 65, II, 'c', que dispõe:

Art. 65. Os contratos regidos por esta Lei poderão ser alterados, com as devidas justificativas, nos seguintes casos:

I - unilateralmente pela Administração: omissis.

II - por acordo das partes:

a) omissis

b) omissis.

c) quando necessária à modificaçāo da forma de pagamento, por imposição de circunstâncias supenvenientes, mantido o valor inicial atualizado, vedada a antecipação do pagamento, com relação ao cronograma financeiro fixado, sem a correspondente contraprestação de fornecimento de bens ou execução de obra ou serviço;

d) omissis.

Comentando como deve ser dado cumprimento a este dispositivo, ANTÔNIO ROQUE CITADINI, observa que "quando a Administração em face a circunstâncias

21 JUSTEN FILHO, Marçal. Comentários à Lei de Licitações e Contratos Administrativos, Ed. Dialética, São Paulo, 5" edição, 1998, pp. 560 e 561. 
supervenientes, ${ }^{22}$ for compelida a alterar a forma de pagamento, deverá proceder à competente negociação, objetivando um resultado que permita a regular execução contratual; embora em termos diversos, ficará preservada a substância do firmado incialmente. A mudança, porém. deverá ser motivada, sendo vedada a alteração que busque beneficiar ou, por motivos de persequição, punir indiretamente o contratado, por desavenças na relação. Mudando-se a forma de pagamento, deve ser mantido o valor inicial ajustado. com a elaboração de outro cronograma de execução, alterando-se o contrato de forma que os desembolsos correspondam à contraprestação do fornecimento de bens, serviços ou obra. Oportuno lembrar que o pagamento antecipado é vedado." 23

\section{Conclusões}

Por todo o exposto, podemos concluir que:

1. A Resolução CONTRAN n 141 é legal por constituir emanação dos poderes normativos legitimamente atribuídos pelo Código de Trânsito Brasileiro - CTB ao Conselho Nacional de Trânsito - CONTRAN;

2. A mudança jurídica provocada pela Resolução CONTRAN nº 141 constitui Fato do Príncipe, que poderá, mediante acordo das partes, levar à alteração da forma de pagamento prevista nos contratos na forma do art. 65, II, 'c' da Lei ${ }^{\circ}$ 8.666/93 e dos requisitos acima colocados; ou

3. Caso não seja possível a alteração aludida no Item anterior, a Administração Pública deverá efetivar a rescisão do contrato sem culpa (de quaisquer das partes).

22 Acresça-se a assertiva de Marçal Justen Filho, segundo a qual "as circunstâncias, a que alude o texto legal, devem ser eventos que alterem as condições de execução ou de pagamento. A mutação na forma de pagamento corresponderá a essas outras alterações" (JUSTEN FILHO, Marçal. Comentários à Lei de Licitações e Contratos Administrativos, Ed. Dialética, São Paulo, $5^{2}$ edição, 1998, p. 517).

23 CITADINI, Roque Antônio. Comentários e Jurisprudência sabre a Lei de Licitações Públicas, Ed. Max Limonad, São Paulo, $3^{\mathbf{a}}$ edição, 1999. p. 433. 


\section{Revista da Academia Brasileira de Letras Jurídicas}

Vários autores

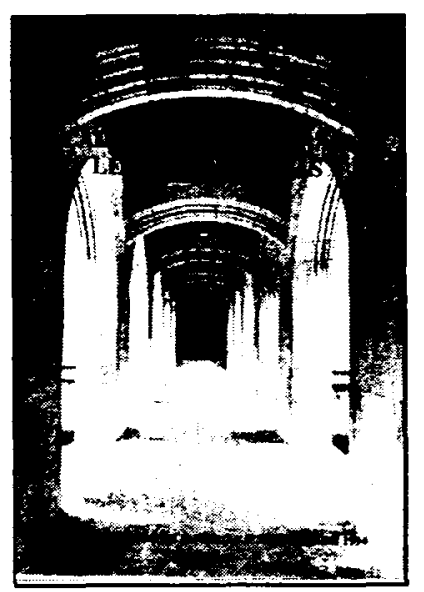

Um repositório de temas assinados por destacados mestres do Direito e cobrindo os mais diferentes ramos da Ciência Jurídica. O zelo editorial da Renovar assegura à Revista da Academia Brasileiras de Letras Jurídicas, uniformidade na apresentação, continuidade na publicação e amplitude na distribuição.

Ref. 0077

Brochura

Form. 14x21

\section{Revista da Faculdade de Direito da UERJ}

Coord. de: Wanda Vianna Direito e Elias Santana Gomes

A Revista da UERJ abriga a produçāo científica de mestres do Direito, com uma variada gama de especialidades jurídicas. Obra que se impõe para quem deseja estar atualizado com o que de mais modemo existe na literatura universitária.

Ref. 0086

Brochura

Form. 16x23

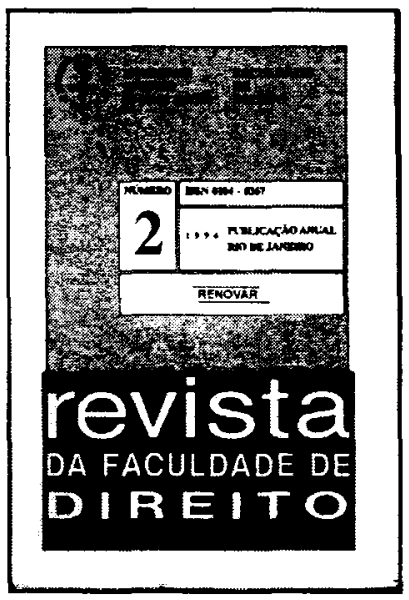

